\title{
How I manage cold agglutinins
}

\author{
W. John Judd
}

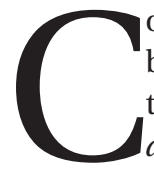

old agglutinins have been one of the banes of blood group serologists since pretransfusion testing protocols were first implemented. Cold autoagglutinins interfere with $\mathrm{ABO} / \mathrm{Rh}$ typing tests, yield unwanted positive tests for unexpected antibodies, and may mask the presence of concomitant, clinically significant alloantibodies. Cold alloagglutinins, such as anti-M, $-\mathrm{P}_{1}$, or $-\mathrm{Le}^{\mathrm{a}}$ rarely cause accelerated destruction of mismatched red blood cells (RBCs), and it is not necessary to detect examples of these antibodies that only react below body temperatures.

The extent to which cold agglutinins can interfere with the results of pretransfusion antibody detection and compatibility tests is evident from a study by Garratty ${ }^{1}$ on the importance of anticomplement reagents in immunohematology. With a low-ionic-strength saline (LISS) method that included room temperature incubation and polyspecific (anti-IgG+C3) antiglobulin serum, the rate of unwanted positive tests (due primarily to the detection of cold-reactive auto- and alloagglutinins) was on the order of 1.41 percent! Omitting the room temperature incubation phase and use of anti-IgG reduced the unwanted positive rate reduced to 0.1 percent.

\section{AVOIDING COLD AGGLUTININS}

Given these introductory comments, the proper handling of cold agglutinins in the transfusion service requires that pretransfusion antibody screening be performed utilizing methods that avoid their detection, namely:

From the Department of Pathology, University of Michigan Medical Center, Ann Arbor, Michigan.

Address reprint requests to: W. John Judd, FIBMS, MIBiol, Professor of Immunohematology, Department of Pathology, UH-2G332, University of Michigan Medical Center, 1500 East Medical Center Drive, Ann Arbor, MI 48109-0054; e-mail: johnjudd@umich.edu.

Received for publication November 2, 2005; accepted November 17, 2005.

doi: 10.1111/j.1537-2995.2006.00726.x

TRANSFUSION 2006;46:324-326.
1. No reading for direct agglutination, including immediate-spin tests and direct reading after $37^{\circ} \mathrm{C}$ incubation.

2. No microscopic examination of tests.

3. Use of anti-IgG instead of polyspecific antiglobulin reagent.

In these regards, polyethylene glycol or gel techniques ${ }^{2,3}$ are ideal methods to use. Data supporting safety of the above recommendations are found in Trudeau and colleagues, ${ }^{4}$ Laferriere and coworkers, ${ }^{5}$ Judd and colleagues, ${ }^{6-8}$ and Judd. ${ }^{9}$

The one problem that can arise from omitting readings for direct agglutination when screening for unexpected antibodies is the occurrence of a positive immediate-spin cross-match when the screening tests are negative. In this situation, before implementing an electronic cross-match, our approach was to verify that blood of the correct ABO type had been selected and to crossmatch the units by the indirect anitglobulin test (IAT). If the units were compatible by IAT, they were released for transfusion. If not, an antibody identification study was initiated.

\section{LABORATORY MANAGEMENT OF COLD AGGLUTININS}

Despite implementation of methods to avoid their detection, potent cold agglutinins will continue to interfere with the results of pretransfusion tests. Their appropriate management entails:

1. Resolving blood typing discrepancies, with warmwashed $\left(37^{\circ} \mathrm{C}\right.$ saline) or 2-mercaptoethanol-treated $\mathrm{RBCs}$, and "reverse" $\mathrm{ABO}$ tests at $37^{\circ} \mathrm{C}$ (control with group $\mathrm{O}$ RBCs) or with autoadsorbed or group $\mathrm{O}$ adsorbed serum-plasma.

2. Differentiating autoantibody from alloantibody, especially autoanti-I versus alloanti-I or alloanti-P. It is imperative to compare the reactivity of the autocontrol with reagent RBCs and (sometimes) with RBCs of the same ABO type as the patient (e.g., $A_{1}$ RBCs for recognition of anti-HI).

3. Excluding the presence of underlying potentially significant alloantibodies. This usually entails adsorption studies, although simple omission of 
potentiators with increased incubation at $37^{\circ} \mathrm{C}$ (to permit adequate detection for wanted antibodies) can often prove fruitful. An alternative approach is to look for IgG alloantibodies after inactivation of the IgM autoantibody with 2-mercaptoethanol.

Their inappropriate management entails application of prewarmed tests (see Judd, ${ }^{10,11}$ Judd et al., ${ }^{12}$ Leger and Garratty ${ }^{13}$ for an in-depth discussion).

\section{SELECTING BLOOD FOR TRANSFUSION}

Having differentiated alloagglutinins from autoagglutinins and ruled out the presence of underlying, potentially significant alloantibodies, the following policies can be helpful in the selection of blood for transfusion:

\section{Alloanti-M, $-\mathrm{P}_{1}$, and -Le and anti-HI (active at IAT)}

1. Issue IgG IAT compatible units,

2. Avoid use of acidic LISS reagents, especially for anti$\mathrm{M}$, since many examples of anti-M give enhanced reactions at an acidic $\mathrm{pH} .{ }^{14}$

3. Do not confirm the antigen-negative status of donor units for patients with anti-M, $-\mathrm{P}_{1}$, or - Le. ${ }^{15}$

4. Cross-match $\mathrm{A}_{1}$ units for anti-HI.

\section{Anti-N}

Rare examples of alloanti-N in individuals of African ethnicity deserve special mention, because these can be clinically significant when made by $\mathrm{N}$ - individuals who lack or have abnormal glycophorin B (Ss sialoglycoprotein). Such individuals (e.g., $M S^{u} / M S^{u}$ or $M S^{u} / M s H e$ ) have RBCs that are completely devoid of $\mathrm{N}$; they lack $\mathrm{N}$ on glycophorin A, and "N" on glycophorin B. Their serum may contain a potent alloanti- $\mathrm{N}$ that causes accelerated destruction of N- but S+/s+ RBCs (carrying "N"). Accordingly, whenever an anti- $\mathrm{N}$ is detected in pretransfusion testing, it is important to ascertain the ethnic background of the patient and, if African, test for "N" with Vicia graminea lectin after treatment of their RBCs with purified trypsin. If nonreactive, use of rare blood from $\mathrm{N}-\mathrm{U}-$ individuals is indicated. ${ }^{16,17}$

\section{Autoanti-I (active at IAT)}

1. Confirm the $A B O$ types of the donor units selected for transfusion and the intended recipient RBCs at time of assignment (reservation). It has already been determined that the anti-I is an autoantibody and therefore will not destroy transfused RBCs at a greater rate than untransfused RBCs. Accordingly, an antiglobulin cross-match is not required. Further, confirming the $\mathrm{ABO}$ types of both patient and donor RBCs is less laborious than performing prewarmed tests.
2. Alternatively, perform an immediate-spin crossmatch with autoadsorbed serum. This will likely be available from earlier studies.

3. Alternatively, perform an IgG IAT cross-match on unadsorbed serum but without enhancement medium. Previously performed studies should indicate if compatible units will be obtained.

4 Alternatively, do an electronic cross-match. ${ }^{18}$ One of its unsung advantages is that it does not yield unwanted positive tests!

Note: The use of blood warmers is rarely needed, except in florid cold agglutinin disease. ${ }^{19}$

\section{Above antibodies, but inactive at IAT}

1. Issue units compatible by IAT cross-match with antiIgG.

2. Alternatively, do electronic cross-match.

\section{Alloanti-I, -P, and so forth}

Never prewarm! These antibodies have the potential to cause accelerated destruction of mismatched RBCs. ${ }^{20,21}$ They should be managed in the same way as any potentially significant antibody to a high-prevalence antigen.

\section{Cold agglutinins and heart surgery}

There are conflicting opinions expressed in surgical journals. ${ }^{22-24}$ Our approach is "don't screen for them; don't report them." We discourage requests for titration and thermal amplitude tests and recommend use of room temperature crystalloid instead of cold cardioplegia.

\section{SUMMARY}

In summary, although cold agglutinins can and have been a challenging, and perhaps even an annoying, phenomenon, the strategies described above can limit their effect on the transfusion service while helping to ensure maximal transfusion safety. Still, of greatest importance is the need to differentiate cold autoantibodies from cold alloantibodies and to exclude the presence of concomitant IgG alloantibodies.

\section{REFERENCES}

1. Garratty G. The significance of complement in immunohematology. CRC Crit Rev Clin Lab Sci 1984;20: 25-56.

2. Nance SJ, Garratty G. A new potentiator of red blood cell antigen-antibody reactions. Am J Clin Pathol 1987;87:633-5.

3. Lapierre Y, Rigal D, Adam J, et al. The gel test: a new way to detect red cell antigen-antibody reactions. Transfusion 1990;30:109-13. 
4. Trudeau LR, Judd WJ, Butch SH, Oberman HA. Is a room temperature crossmatch necessary for the detection of ABO errors? Transfusion 1983;23:237-9.

5. Laferriere M, Harrison L, Zack S. Parallel comparison of reading antiglobulin (AHG) phase microscopically vs. macroscopically in routine antibody screening [abstract]. Transfusion 1993;33(Suppl):83.

6. Judd WJ, Steiner EA, Oberman HA, Nance SJ. Can the reading for serological reactivity following $37^{\circ} \mathrm{C}$ incubation be omitted? Transfusion 1992;32:304-8.

7. Judd WJ, Fullen DR, Steiner EA, Knafl PC, Davenport RD. Revisiting the issue: can the reading for serologic reactivity following $37^{\circ} \mathrm{C}$ incubation be omitted? Transfusion 1999; 39:295-9.

8. Judd WJ, Steiner EA, Knafl PC. The gel test: sensitivity and specificity for unexpected antibodies to blood group antigens. Immunohematology 1997;13:132-5.

9. Judd WJ. Modern approaches to pretransfusion testing. Immunohematology 1999;15:41-52.

10. Judd WJ. Prewarmed tests: con. Transfusion 1995;35:271-5.

11. Judd WJ. Attack on prewarmed tests-too much hot air [letter]. Transfusion 1996;36:192-3.

12. Judd WJ, Steiner EA, Knafl P, Davenport RD. Failure to detect potentially significant antibodies in prewarmed tests. Transfusion 1995;35(Suppl):68.

13. Leger RM, Garratty G. Weakening or loss of antibody reactivity after prewarm technique. Transfusion 2003;43:1611-4.

14. Beattie KM, Zuelzer WW. The frequency and properties of pH dependent anti-M. Transfusion 1965;5:322-3.

15. Cronin CA, Pohl BA, Miller WV. Crossmatch compatible blood for patients with anti-P1. Transfusion 1978;18:728-30.
16. Judd WJ, Rolih SD, Dahr W, et al. Studies on the blood of an $\mathrm{MsHe} / \mathrm{MS}^{u}$ proposita and her family: serological evidence that Henshaw-producing genes do not code for "N." Transfusion 1983;23:382-6.

17. Judd WJ. On the recognition of N-deficient red blood cells and the selection of blood for transfusion to patients with anti-N [editorial]. Immunohematology 1986;2:50-3.

18. Butch SH, Judd WJ, Steiner EA, Stoe M, Oberman HA. Electronic verification of donor-recipient compatibility: the computer crossmatch. Transfusion 1994;34:105-9.

19. Petz LD, Swisher SN, Kleinman S, Spence RE, Strauss RG, editors. Clinical practice of transfusion medicine. New York: Churchill Livingstone; 1996.

20. Chaplin H, Hunter VL, Malecek AC, Kilzer P, Rosche ME. Clinical significance of allo-anti-I in an I-negative patient with massive hemorrhage. Transfusion 1986;26: 57-61.

21. Postoway N, Anstee DJ, Wortman M, Garratty G. A severe transfusion reaction associated with anti-En ${ }^{\mathrm{a}} \mathrm{TS}$ in a patient with an abnormal alpha-like red cell sialoglycoprotein. Transfusion 1988;28:77-80.

22. Diaz JH, Cooper ES, Oschner JL. Cold agglutinin pathophysiology: evaluation and management of patients undergoing cardiac surgery with induced hypothermia. Arch Int Med 1984;144:1639-41.

23. Gokhale AG, Suhastru T, Saraswati VM, Chandrasekhar N, Rajagopal P. Cold agglutinins and warm heart surgery. J Thorac Cardiovasc Surg 1993;105:557.

24. Holman WL, Smith SH, Edwards R, Huang ST. Agglutination of blood cardioplegia by cold reacting autoantibodies. Ann Thorac Surg 1991;51:833-6. 